\title{
Climate-induced phenological shift of apple trees has diverse effects on pollinators, herbivores and natural enemies
}

Ádám Kőrösi ${ }^{\text {Corresp., }}{ }^{1,2}$ ， Viktor Markó ${ }^{3}$ ，Anikó Kovács-Hostyánszki ${ }^{4}$ ， László Somay ${ }^{4}$ ， Ákos Varga ${ }^{3}$, Zoltán Ele 1, Virginie Boreux ${ }^{5}$, Alexandra-Maria Klein ${ }^{5}$, Rita Földesi ${ }^{6}$, András Báldi ${ }^{4}$

${ }^{1}$ MTA-ELTE-MTM Ecology Research Group, Budapest, Hungary

2 Theoretical Evolutionary Ecology Group, Department of Animal Ecology and Tropical Biology, University of Würzburg, Würzburg, Germany

3 Department of Entomology, Szent István University, Budapest, Hungary

4 Institute of Ecology and Botany, Lendület Ecosystem Services Research Group, MTA Centre for Ecological Research, Vácrátót, Hungary

${ }^{5}$ Nature Conservation and Landscape Ecology, Faculty of Environment and Natural Resources, University of Freiburg, Freiburg, Germany

${ }^{6}$ Agroecology and Organic Farming, Institute of Crop Science and Resource Conservation, University of Bonn, Bonn, Germany

Corresponding Author: Ádám Körösi

Email address: korozott@gmail.com

Climate change is altering the phenology of trophically linked organisms, leading to increased asynchrony between species with unknown consequences for ecosystem services. Although phenological mismatches are reported from several ecosystems, experimental evidence for altering multiple ecosystem services is hardly available. We examined how the phenological shift of apple trees affected the abundance and diversity of pollinators, generalist and specialist herbivores and predatory arthropods. We stored potted apple trees in the greenhouse or cold store in early spring before transferring them into orchards to cause mismatches and sampled arthropods on the trees repeatedly. Assemblages of pollinators on the manipulated and control trees differed markedly, but their overall abundance was similar indicating a potential insurance effect of wild bee diversity to ensure fruit set in flower-pollinator mismatch conditions. Specialized herbivores were almost absent from manipulated trees, while less-specialized ones showed diverse responses, confirming the expectation that more specialized interactions are more vulnerable to phenological mismatch. Natural enemies also responded to shifted apple tree phenology and the abundance of their prey. While arthropod abundances either declined or increased, species diversity tended to be lower on apple trees with shifted phenology. Our study indicates novel results on the role of biodiversity and specialization in plant-insect mismatch situations. 
1 Climate-induced phenological shift of apple trees has diverse effects on pollinators,

2 herbivores and natural enemies

4 Ádám Körösi ${ }^{1,2 *}$, Viktor Markó ${ }^{3 *}$, Anikó Kovács-Hostyánszki ${ }^{4}$, László Somay ${ }^{4}$, Ákos Varga ${ }^{3}$,

5 Zoltán Elek ${ }^{1}$, Virginie Boreux ${ }^{5}$, Alexandra-Maria Klein ${ }^{5}$, Rita Földesi ${ }^{6}$, András Báldi ${ }^{4}$

6

$7 \quad *$ These authors contributed to the manuscript equally

$8 \quad{ }^{1}$ MTA-ELTE-MTM Ecology Research Group, Budapest, Hungary

$9{ }^{2}$ Theoretical Evolutionary Ecology Group, Department of Animal Ecology and Tropical Biology,

10 Biocenter, University of Würzburg, Germany

$11{ }^{3}$ Department of Entomology, Szent István University, Budapest, Hungary

$12{ }^{4}$ Institute of Ecology and Botany, Lendület Ecosystem Services Research Group, MTA Centre for

13 Ecological Research, Vácrátót, Hungary

$14{ }^{5}$ Faculty of Environment and Natural Resources, Nature Conservation and Landscape Ecology,

15 University of Freiburg, Freiburg, Germany

$16{ }^{6}$ Institute of Crop Science and Resource Conservation, Agroecology and Organic Farming,

17 University of Bonn, Bonn, Germany

19 Corresponding author: Ádám Körösi; korozott@gmail.com

20 Mailing address: MTA-ELTE-MTM Ecology Research Group, Biological Institute, Eötvös

21 Loránd University, Pázmány Péter sétány 1/C, Budapest 1117, Hungary 


\section{Abstract}

23 Climate change is altering the phenology of trophically linked organisms, leading to increased

24 asynchrony between species with unknown consequences for ecosystem services. Although

25 phenological mismatches are reported from several ecosystems, experimental evidence for

26 altering multiple ecosystem services is hardly available. We examined how the phenological shift

27 of apple trees affected the abundance and diversity of pollinators, generalist and specialist

28 herbivores and predatory arthropods. We stored potted apple trees in the greenhouse or cold store

29 in early spring before transferring them into orchards to cause mismatches and sampled

30 arthropods on the trees repeatedly. Assemblages of pollinators on the manipulated and control

31 trees differed markedly, but their overall abundance was similar indicating a potential insurance

32 effect of wild bee diversity to ensure fruit set in flower-pollinator mismatch conditions.

33 Specialized herbivores were almost absent from manipulated trees, while less-specialized ones

34 showed diverse responses, confirming the expectation that more specialized interactions are more

35 vulnerable to phenological mismatch. Natural enemies also responded to shifted apple tree

36 phenology and the abundance of their prey. While arthropod abundances either declined or

37 increased, species diversity tended to be lower on apple trees with shifted phenology. Our study

38 indicates novel results on the role of biodiversity and specialization in plant-insect mismatch

39 situations.

40

41 
Introduction

43 There is growing evidence that in response to ongoing global climate change (IPCC, 2014) the

44 phenology of functionally diverse organisms has been shifted in the last few decades (for a

45 review see Donnelly, Caffarra \& O'Neill, 2011). The rate of phenological shift can vary across

46 different taxa within the same community (Primack et al., 2009; Cook, Wolkovich \& Parmesan,

47 2012), a phenomenon also known as response diversity (Elmqvist et al., 2003). As a consequence,

48 phenological overlap of interacting species can decrease, sometimes resulting in mismatches that

49 uncouple the interaction (Stenseth \& Mysterud 2002; Thackeray et al., 2010). Examples of such

50 phenological mismatches are known from a wide range of ecosystems, mainly in the temperate

51 and arctic regions (Visser \& Holleman 2001; Winder \& Schindler 2004; Post \& Forchhammer

52 2008). However, our knowledge on the possible consequences of phenological mismatches on

53 ecological interactions is still limited (Hegland et al., 2009; Miller-Rushing et al., 2010). Some

54 studies on phenological mismatch assessed a few interacting species at two or more trophic levels

55 (Doi, Gordo \& Katano 2008; Both et al., 2009; Evans et al., 2013; Kudo \& Ida 2013), while

56 others examined whole ecological networks and related the change in network structure with

57 climate warming (Burkle, Marlin \& Knight 2013) or quantified the rate of phenological change in

58 many interacting species across different ecosystems (Thackeray et al., 2010). The consequences

59 of mismatch in multiple interactions within a given community, however, are still largely

60 unexplored.

61 Considerable attention has been devoted to mutualistic plant-pollinator networks, since

62 earlier simulations predicted pollinator extinctions due to mismatch with food plants (Memmott

63 et al., 2007). A recent review (Forrest 2015) of the relationship between phenological changes

64 and plant-pollinator interactions found that apart from a few examples of negative consequences

65 of mismatch between plants and pollinators (Thomson 2010; Kudo \& Ida 2013), rates of

66 phenological advance related to global warming seem broadly consistent between generalist 
67 plants and insect pollinators at large spatial scales (Bartomeus et al., 2011; Iler et al., 2013;

68 Ovaskainen et al., 2013). This consistency is likely due to the fact that insects and the plants they

69 pollinate may use similar environmental cues to time their spring emergence (Forrest \& Thomson

70 2011), and that plant-pollinator interactions are quite flexible (Petanidou et al., 2008; Benadi et

71 al., 2014). Rafferty \& Ives (2011) manipulated the phenology of 14 plant species and found no

72 temporal mismatches between flowering onset and pollinator visitation for most of them. Burkle,

73 Marlin \& Knight (2013) attributed a large proportion of lost plant-bee interactions in their

74 pollination network to phenological mismatch, but could not determine whether the apparent

75 mismatches were a cause or a consequence of pollinator declines.

76 Hitherto, a few studies have been able to uncover the consequences of phenological shifts

77 for species and their trophic interactions (Rafferty et al., 2013). For example, recent phenological

78 asynchrony between egg-hatching of winter moth (Opheroptera brumata L.) and bud burst of oak

79 trees (Quercus robur L.) due to their differential response to increased spring temperature lead to

80 natural selection, and winter moth rapidly adapted to this environmental change resulting in

81 recovery of synchrony (Van Asch et al., 2007). Mutualistic interactions can also be disrupted

82 when climate response is different between species. When plant phenology was experimentally

83 manipulated, advanced flowering of Sinapis arvensis (L.) caused a decline in flower-visiting

84 pollinators, but an increase of seed set (Parsche, Fründ \& Tscharntke, 2011), while both advanced

85 and delayed treatments led to very low reproduction of a spring ephemeral Claytonia lanceolata

86 Pursh due to either frost damage or low pollinator visitation (Gezon, Inouye \& Irwin, 2016).

87 Nevertheless, all these studies were limited to one type of interaction, a few interacting species

88 and/or two guilds. For future research, the importance of studies that scale up from pairwise

89 species interactions to communities and ecosystems involving multiple trophic levels using

90 experimental approaches has been emphasized (Rafferty et al., 2013).

91 In Europe, apple (Malus $x$ domestica) is one of the most important insect-pollinated crop 
92 plants, accounting for $16 \%$ of the EU's total economic gains attributed to insect pollination

93 (Leonhardt et al., 2013). Apple orchards can harbor rich arthropod communities that largely

94 contribute to the biodiversity and functioning of agro-ecosystems (Rosa García \& Miñarro 2014),

95 while crop yield and quality strongly depend on ecosystem services, particularly pollination

96 (Klein et al., 2007; Garratt et al., 2014) and pest control (Cross et al., 2015). We aimed to unravel

97 the possible consequences of climate-induced phenological shift of apple on the abundance and

98 diversity of arthropods at multiple trophic levels. Therefore, we manipulated the phenology of

99 young potted apple trees in a greenhouse or a cold store and repeatedly sampled arthropod

100 communities after transferring the trees into organic apple orchards. In this way we imitated a

101 'worst-case scenario' (sensu Rafferty et al., 2013), i.e. when climate-induced phenological shift of

102 apple trees to earlier dates was much larger (Advanced scenario) or smaller (Delayed scenario)

103 than that of arthropods, and thus phenological asynchrony was maximized. In the temperate zone,

104 climate change usually advances spring phenology (Schwartz, Ahas \& Aasa 2006), so our

105 Delayed scenario imitated a situation when phenology of apple trees advances to much lower

106 degree than the phenology of arthropods. Primarily, we were interested in the response of

107 arthropod abundance and diversity to this experimentally induced phenological asynchrony.

108 We hypothesized, that (i) pollinator abundance, diversity and species composition on

109 manipulated trees will be different from the control trees (Rafferty \& Ives 2011; Parsche, Fründ

110 \& Tscharntke, 2011; Gezon, Inouye \& Irwin, 2016), (ii) responses of herbivores will correlate

111 with their degree of specialization to apple (measured as degree of monophagy), since more

112 specialized interactions are expected to be more vulnerable to phenological mismatches

113 (Memmott et al., 2007; Van Asch \& Visser 2007; Miller-Rushing et al., 2010), (iii) natural

114 enemies as secondary consumers may be either less or even more affected than herbivores,

115 depending on the response of their prey (herbivores) and how strongly they are coupled to them. 


\section{Materials \& Methods}

\section{Experimental design and sampling}

119 We manipulated the phenology of potted, three years old apple trees $(\mathrm{n}=182, \mathrm{cv}$. Resi, $\sim 2.5 \mathrm{~m}$

120 height, $\sim 3 \mathrm{~cm}$ trunk diameter) by keeping them either in a greenhouse (advanced treatments), a

121 cold store (delayed treatments), or outdoors (control) from March 2013. Before flowering, trees

122 were buried outdoors with their pot in five treatments during April and May (Advanced1,

123 Advanced2, Control, Delayed1, and Delayed2. See Table 1). The experiment was conducted in

124 three organic apple orchards in Eastern Hungary (see geographical locations in Data S1). Within

125 the three orchards, we designated altogether eight blocks $(3+3+2)$ and we distributed the

126 experimental apple trees among them in a way that each block contained more or less similar

127 numbers of trees from all treatment groups. During flowering, branches of apple trees were

128 placed out in water canisters in all blocks to enable cross-pollination for the experimental trees.

129 For information on the flowering periods of apple cultivars that occurred in the study orchards

130 see Table S1.

131 Phenology of apple trees was documented by photographs and dates of onset of main

132 phenological phases (bud burst; onset, peak, end of flowering) were also recorded. Five randomly

133 selected leaves were collected from each experimental tree on 18 July and leaf size was

134 calculated from scanned digital images (O’neal, Landis \& Isaacs 2002) using ImageJ 1.49

135 (Schneider, Rasband \& Eliceiri 2012) and Adobe Photoshop 8.0 (Adobe Systems) software. Ripe

136 apple fruits were collected from all experimental trees in August. Total shoot growth was

137 measured on three randomly chosen annual shoots per tree on 22 Nov.

138 Pollinators were sampled on each tree twice, on two subsequent days between 9:00 a.m.

139 and 4:00 p.m. under favourable weather conditions $\left(>20^{\circ} \mathrm{C}\right.$, wind speed $\leq 3$ on Beaufort scale)

140 during peak flowering of each treatment group. At both occasions, we counted the flowers and

141 observed the pollinators landing on the flowers on each tree for 15 minutes. All trees were 
142 sampled by two persons at one time. European honey bees (Apis mellifera L.) and bumble bees

143 (Bombus spp.) (Hymenoptera: Apidae) were identified without capturing, while solitary wild bees

144 (i.e. other wild bees than Bombus spp. including some semi-social species; Hymenoptera:

145 Apoidea) and hoverflies (Diptera: Syrphidae) were captured by insect nets and preserved in $70 \%$

146 ethanol for later identification.

147 Green apple aphids (Aphis pomi de Geer) (Hemiptera: Aphididae) were sampled three

148 times during summer ( $14 \& 27$ June, 12 July). Each time the shoots were counted and the

149 proportion of young, still growing shoots was estimated on each tree. Then three growing shoots

150 and three non-growing (old) shoots were randomly selected and aphids were counted on them.

151 Other herbivores and natural enemies were sampled by beating the whole canopy of each tree for

15215 seconds with a 70-cm-long stick, collecting the fallen arthropods in a 35-cm-radius beating

153 funnel and preserving them in 50\% ethanol for later identification. Sampling was repeated once a

154 week from 24 April until 18 July. Buds infected by the apple blossom weevil (Anthonomus

155 pomorum L.) (Coleoptera: Curculionidae) were counted on all trees one week after peak

156 flowering. These 'capped buds' have a rusty colour, never open and stay on the tree for a while.

158 Data preparation

159 We analyzed the effects of treatments on some characteristics of apple trees, and abundance,

160 diversity and species composition of arthropods. Apple tree flower numbers from the two

161 pollinator sampling occasions were averaged for each tree and square root transformed, while

162 leaf size and shoot growth were not transformed. The number of ripe apples was divided by the

163 number of flowers for each tree to calculate fruit set. Abundance of honey bees, wild bees (incl.

164 bumble bees) and hoverflies from the two sampling occasions was summed for each tree. Based

165 on the shoot and aphid counts, aphid abundance was estimated for each tree at each sampling

166 event and then $\log (\mathrm{x}+1)$-transformed. Both the proportion of growing shoots and aphid 
167 abundance showed a sharp decline through the three sampling occasions in all treatments and the

168 mean of the three samples was used for analysis.

169 Since the number of arthropods per tree per beating event was very low, we pooled the

170 data of all samples between 8 May and 18 July for each tree. Thus we pooled the same number of

171 samples $(\mathrm{n}=11)$ for all treatment groups. From herbivores, we used data of apple blossom weevil,

172 pear lace bug (Stephanitis pyri (Fabr.)) (Hemiptera: Tingidae) and all other phytophagous bugs

173 (Hemiptera: Heteroptera). The highest number of adults of A. pomorum was found in late April,

174 so we pooled the samples from 24 April to 18 July for this species. Only its occurrence was

175 analyzed as this species occurred in only one orchard, where it was absent on $\sim 75 \%$ of the trees.

176 A. pomorum occurrence was zero on Delayed1 trees, so we omitted this treatment group from the

177 analysis. Buds infected by $A$. pomorum were found only on advanced and control trees in the

178 same orchard. Number of capped buds was $\log (\mathrm{x}+1)$-transformed.

179 In order to account for natural enemies, we used the abundance of aphidophagous beetles

180 (Coleoptera: Coccinellidae), zoophagous (incl. zoo-phytophagous) bugs (Hemiptera: Heteroptera)

181 and spiders (Araneae). For spider abundance, juvenile and adult spiders were all counted, while

182 diversity and species composition analyses were based on only adult spider specimens that were

183 possible to identify at species level. We identified sufficient number of species to analyze species

184 composition and diversity in four taxonomic groups: wild bees (incl. bumble bees), phytophagous

185 true bugs (excluding S. pyri due to its overwhelming abundance), aphidophagous beetles and 186 spiders.

188 Data analysis

189 We used generalized linear mixed effects models (GLMM) with treatment as the fixed effect and

190 block ID as a random factor. Response variables were the abundance, in some cases the

191 occurrence of arthropods, flower number, leaf area, shoot growth, fruit set and the number of 
192 buds infected by $A$. pomorum (see Data preparation). For some response variables, continuous

193 variables as additional fixed terms were included in the GLMM. In such cases, we also tested if

194 the interaction between treatment and the continuous variable was significant. Such continuous

195 variables were: the number of flowers for pollinator abundance; the proportion of growing shoots

196 for aphid abundance; aphid abundance for the abundance of aphidophagous beetles and

197 zoophagous bugs; abundance of $S$. pyri for the abundance of spiders. We hypothesized that these

198 covariates represent the main food sources of the corresponding arthropod groups and thus would

199 influence their abundance. Moreover, the inclusion of these covariates ensured that we could

200 separate the effects of altered phenology and altered physiology of apple trees caused by our

201 experimental treatment. Continuous covariates were centered. When more than one fixed term

202 was involved, we performed an AICc-based model selection (Burnham \& Anderson, 2002) and

203 results of the model with the lowest AICc value are reported.

204 For occurrence data, we used a binomial error distribution, otherwise we applied the most

205 appropriate error structure based on AICc values and diagnostic plots. Abundance of S. pyri was

206 zero on $\sim 36 \%$ of apple trees and showed a right-skewed distribution on the rest of them so we

207 fitted a model to the log-transformed non-zero abundances with a quasi-Poisson error structure.

208 Quasi-Poisson error structure was used also for fruit set and number of capped buds (Table S1).

209 Zero-inflated models were used if it improved model fit (Zuur et al., 2007).

210 For the community-level analysis, we calculated and plotted Rényi's diversity profile for

211 each treatment. Common diversity indices are special cases of Rényi diversity (Hill, 1973), and

212 one community can be regarded as more diverse than another only if its Rényi diversities are all

213 higher (i.e. their diversity profiles do not intersect) (Tóthmérész, 1995). We also conducted two

214 separate redundancy analyses (RDA) with constraint variables orchard and treatment. Species

215 matrix was transformed with the Hellinger method to improve the effectiveness of these analyses

216 in representing ecological relationships (Legendre \& Gallagher, 2001), and significance of the 
217 constraint term was tested by a permutation test $\left(10^{4}\right.$ permutations). A non-metric

218 multidimensional scaling (NMDS) with Bray-Curtis distances was applied to visualize similarity

219 among treatments in each orchard. All analyses were made using packages glmmADMB (Skaug

220 et al., 2015), lme4 (Bates et al., 2015), MuMIn (Barton, 2014) and vegan (Oksanen et al., 2017)

221 of R 3.4.3 statistical software (R Core Team, 2017). The dataset and the R code used for the

222 analysis are in Supplementary Material (Data S2 \& S3).

224 Results

225 Tree phenology and pollination success

226 Trees kept in the greenhouse had their flowering advanced by 6-9 days, while flowering of cool

227 stored trees was delayed by 16-38 days compared to the control ones. Flowering period lasted for

228 5-7 days in all treatments (Table 1). Number of flowers was higher on control trees than in all

229 other treatments, but there was no difference among the other treatment groups (Fig. 1a). Leaf

230 size was larger on advanced trees and smaller on delayed trees than on control ones (Fig. 1b),

231 while total shoot growth was not affected by treatment (Fig. 1c). Sufficient number of fruits for

232 statistical analysis was harvested in only one orchard. Here fruit set did not differ between

233 advanced and control trees, but delayed trees responded with lower reproductive success (Fig. 1d,

234 Table 2 \& Table S2).

Pollinators

237 Flower number of apple trees had a positive effect on the abundance of all pollinator groups, but

238 its interaction with treatment was not significant (Table $2 \&$ Table S2). This means that the

239 relationship between flower number and pollinator abundance had the same strength in each

240 treatment. In other words, pollinator abundance was best explained by treatment effect plus the

241 effect of flower number. However, since the number of flowers was not equal among treatment 
242 groups (see above), model estimates on treatment effects should be interpreted as if flower

243 number were the same in all treatments. Honey bee abundance was higher on delayed trees and

244 Advanced 2 trees than on control ones. Observed honey bee abundance was not higher on

245 Advanced2 trees than on control ones (Fig. 2), but the model estimated that it would be higher if

246 the number of flowers were equal in these two groups. Hoverfly abundance was also higher on

247 delayed trees than on control ones. Abundance of wild bees was higher on Advanced1, Delayed1

248 and Delayed2 trees than on control ones (Fig. 2) (Table $2 \&$ Table S2). To compare with other

249 studies, we also calculated and plotted the visitation rate as the number of pollinators/15

250 minutes/1000 flowers in each treatment group (Fig. S1).

251 Altogether 39 wild bee species were observed on the apple trees (Table S3). Diversity was

252 higher on Delayed2 trees than on control and Advanced1 trees, while diversity on Delayed1 trees

253 was lower than on all aforementioned treatments (Fig. 3a). A few species (Andrena haemorrhoa

254 Fabr., A. varians Kirby, Lasioglossum calceatum Scopoli, Osmia cornuta Latr.) occurred in high

255 abundances on Advanced1 trees, but in much lower abundances in all other treatments, resulting

256 in the significantly higher abundance on Advanced1 trees. RDA revealed that treatment had an

257 effect on species composition of wild bee assemblages and it explained $12.3 \%$ of total variation,

258 while orchard explained only 3.4\% (Table S4). Samples of treatment groups were separated on

259 the NMDS plot (Fig. S2).

261 Herbivores

262 Both the occurrence of $A$. pomorum and the number of capped buds were lower in all treatments

263 than in control. The difference was significant on Delayed2 trees (occurrence) (Fig. 4a), and on

264 Advanced1 trees (capped buds) (Table 2). We found an interaction between phenological

265 treatment and proportion of young growing shoots (PGS) in their effects on aphid (A. pomi)

266 abundance, as it was positively related to PGS in the delayed, but not in the other treatments (Fig. 
267 4b \& Fig. S3, Table 2 \& Table S2). However, both PGS and aphid abundance were higher on

268 delayed trees. According to this model, the higher aphid abundance on delayed trees is a

269 consequence of the higher PGS on them. Non-zero abundance of S. pyri was lower on delayed

270 trees than on control ones (Fig. 4c). Finally, the abundance of phytophagous bugs was unaffected

271 by treatment of apple trees (Table $2 \&$ Table S2).

272 A total of 30 phytophagous bug species (excluding S. pyri) were identified in the samples

273 (Table S3). Phytophagous bug diversity was lower on delayed than on control and advanced trees

274 (Fig. 3b). RDA revealed no effect of treatment on species composition, while orchard had a

275 significant effect and explained $11.2 \%$ of the total variation (Table S4, Fig. S2).

276

277

278

279

280

281

282

283

284

285

286

287

288

289

290

291

\section{Natural enemies}

Abundance of aphidophagous beetles was higher on Delayed2 trees and lower on Advanced2 trees than on control ones (Fig. 4d). Beetle abundance was negatively related to aphid abundance (Table 2 \& Table S2, Fig. S4). Harmonia axyridis Pallas (harlequin ladybird) was the dominant species ( $56 \%$ of all aphidophagous beetles). When its data were analyzed separately, we found higher abundance of $H$. axyridis on Delayed2 trees than on control ones, while abundance of all other species was unaffected by treatment (Fig. S5). Abundance of zoophagous true bugs was higher on delayed trees than on control ones (Fig. 4e), but aphid abundance had no effect on it. Spider abundance was lower on Delayed2 trees than on control trees if only treatment was included as a predictor (Fig. 4f). However, in the best model the abundance of S. pyri was also included as a covariate, and its interaction with treatment was significant: spider abundance increased with the abundance of $S$. pyri in Advanced2 and Control treatments (Table $2 \&$ Table S2, Fig. S6).

A total of 12 aphidophagous beetle and 40 spider species were identified in the samples (Table S3). Diversity of aphidophagous beetles tended to be lower on Delayed2 trees than on 
292 control and Delayed1 trees (Fig. 3c). Higher abundance and lower diversity on Delayed2 trees

293 was due to the outstanding number of $H$. axyridis. Treatment had a significant effect on species

294 composition, but it explained only $4.13 \%$ of total variation, while orchard was not significant.

295 Diversity of spiders was lower in all treatments than on control trees (Fig. 3d). Species

296 composition was not affected by treatment, while orchard explained only $3.5 \%$ of total variance

297 (Table S4, Fig. S2).

\section{Discussion}

Tree condition and pollinators

301 Food availability is an important factor that governs the activity and population density of

302 pollinating species (Westphal, Steffan-Dewenter \& Tscharntke, 2003; Steffan-Dewenter \&

303 Schiele, 2008). This is also illustrated by the increase of pollinator abundance with the number of

304 apple flowers in our study. Altered flower abundance and flowering time and non-efficient

305 flower-visitation due to climate change are therefore among the most important potential threats

306 to fruit set of apple trees. In our experiment, control trees had on average $\sim 3$ times more flowers

307 than treated ones indicating that altered temperature implied a physiological stress and/or

308 changed the resource allocation within a tree (Bos et al., 2007).

309 The earliest flowering trees were mostly visited by wild bees, while honey bees and

310 hoverflies occurred in lower numbers. The outstanding number of wild bees on Advanced1 trees

311 in mid-April was due to a few dominant species that start foraging at lower temperatures in early

312 spring (Torchio, 1991). These species might have accumulated on early-flowering apple trees,

313 due to the lack of alternative floral resources in the landscape (Moise \& Henry, 2010). Later on

314 the abundance of honey bees and hoverflies showed an increase during the season that might

315 provide suitable flower visitation for the delayed apple tree flowers too. Flowering of the control

316 trees coincided with that of all other apple trees in the orchards that may have caused a dilution 
317 effect as pollinators must have been strongly attracted by other trees as well (Mitchell et al.,

318 2009; Kovács-Hostyánszki et al., 2013; Riedinger et al., 2014).

319 Species composition of wild bee assemblages visiting the apple trees profoundly changed

320 during the $\sim 7$ weeks of the flowering period of manipulated trees. Earliest flowering trees were

321 visited by a few dominant species, but assemblages on trees flowering later were more even and

322 diverse. These correspond to the results of Rafferty \& Ives (2012) who manipulated the

323 phenology of two perennial forbs and observed changes in species composition of flower-visiting

324 wild bees during five weeks of flowering. We can also conclude that high diversity of wild bees

325 can ensure phenological synchrony with apple tree flowering due to complementarity among bee

326 species' activity periods and to differential responses among bee species to warming (Bartomeus

327 et al., 2013). Wild bees, however, can have an outstanding importance in apple tree pollination in

328 the case of advanced flowering, while honey bees and hoverflies may ensure efficient pollination

329 in the case of the delayed scenario.

330 Efficient flower visitation mainly by wild bees on the advanced apple trees was verified

331 by their similar fruit set to control trees. However, absolute number and total biomass of the fruits

332 were higher on control trees (Fig. S7), which suggests that the manipulated trees might have

333 allocated their resources to survival rather than to reproduction (Barboza, Parker \& Hume 2009).

334 Fruit set was lower on delayed trees than in other treatments. Possibly, delayed trees were not

335 limited by pollinators, but rather late transfer from cold store to the gardens delayed their

336 development causing a higher fruit abortion (Bos et al., 2007).

337 Recent studies suggest that pollination success of apple trees responds positively to

338 species richness of wild bees (Mallinger \& Gratton 2015; Földesi et al., 2016). If we use

339 visitation frequency as a surrogate of pollination service (Vazquez, Morris \& Jordano, 2005) then

340 we can conclude that trees with manipulated phenology were not limited by pollinator

341 availability. However, in agricultural landscapes with less semi-natural habitats the number of 
342 wild bees can be very low and apple pollination may fully depend on honey bees (Garibaldi et al.

343 2011; Burkle, Marlin \& Knight, 2013). In such cases, apple trees with an advanced phenology

344 may lack sufficient pollination, and climate change could have profound effect on apple yield.

345 Thus our results confirm that biodiversity can be crucial for the longer-term resilience of

346 ecosystem services (Oliver et al., 2015).

348 Herbivores

349 The specialist $A$. pomorum was almost absent and caused no damage on delayed trees, and it 350 caused less damage on Advanced1 trees than on control ones. This beetle lays eggs in the flower

351 buds, so its phenology must be highly synchronized with that of apple trees. The phenological

352 shift of apple trees had the most adverse effects on this species among the herbivores assessed in

353 our experiment. Aphids prefer the high water and sugar content of growing plant shoots (Stoeckli,

354 Mody \& Dorn, 2008) and population size of the less-specialized oligophagous aphid, A. pomi can

355 rapidly increase by each generation usually reaching a peak in June - early July in apple orchards

356 (Markó et al., 2013; Nagy, Cross \& Markó 2013). In our study, A. pomi showed peak abundance

357 in mid-June, when delayed trees were still in their early and intensive growing phase providing a

358 highly favorable food source. Total shoot growth of apple trees was similar, but its timing was

359 very different among treatments, and it was beneficial for aphids in the delayed treatments. We

360 note that not all aphid colonies were identified to species level in the study. We identified a

361 random subsample of the aphids and the vast majority of them were $A$. pomi. Moreover, $A$. pomi

362 is usually the dominant Aphis species (>80\%) and much more abundant than $A$. spiraecola

363 (Patch) in apple orchards in Hungary (Borbély et al. 2017). The even less specialized bug S. pyri,

364 which is an oligophagous pest of apple feeding on Rosaceae (Wachmann, Melber \& Deckert

365 2006), was less abundant on delayed than on control trees, which resulted from the absence of the

366 first generation (in May) from trees with delayed phenology (Fig. S8). Finally, the absolutely 
367 unspecific herbivore group of phytophagous bugs was unaffected by the phenology of apple

368 trees. These results together support the theoretical expectations that predict a positive correlation

369 between the degree of specialization of ecological interactions and their sensitivity to

370 phenological mismatches (Memmott et al., 2007; Miller-Rushing et al., 2010). From the

371 perspective of resource-consumer dynamics, the highly diverse responses of oligophagous and

372 generalist herbivores that we found to the altered phenology of apple trees are in line with recent

373 theoretical models predicting that changes in phenology alone can lead to qualitatively different

374 dynamics of consumers according to their life-history (Bewick et al., 2016).

\section{Natural enemies}

377 Natural enemies and their prey pests in agro-ecosystems provide an example of predator-prey

378 relationships between primary and secondary consumers. In our study, abundances of natural

379 enemies were affected by apple tree phenology and also related to prey abundances. Although we

380 found some bottom-up effects of prey abundance, these were quite weak and natural enemies

381 were more affected by the phenology of apple trees. For example, ladybirds were coupled to

382 aphids, but also affected by apple tree phenology. The two delayed treatments resulted in

383 similarly high aphid abundances, but Delayed1 trees were not visited by higher number of

384 ladybirds than control trees, while Delayed2 trees were strongly invaded by $H$. axyridis. This is

385 probably because peak aphid abundance on Delayed2 trees coincided with the emergence of the

386 first generation of $H$. axyridis (Honek et al. 2018). The higher number of zoophagous bugs on

387 delayed trees and the lack of statistical relationship with aphid abundance are likely due to the

388 fact that the most dominant zoo-phytophagous mullein bug Campylomma verbasci (Meyer-Dür)

389 ( $\sim 60 \%$ of all zoophagous true bugs) occurred much before the aphid peak (in late May) and

390 occupied mainly the delayed trees. Finally, spider abundance in two treatment groups was related

391 to the abundance of $S$. pyri which is probably an important prey of spiders (Bogya, Markó \& 
392 Szinetár, 2000). Thus spiders were presumably indirectly affected by the phenological shift of

393 apple trees via altered prey abundance, but only on control trees and Advanced2 trees the

394 phenology of which was the least shifted compared to control trees. In delayed treatments, with

395 much larger shifts, the effect of prey abundance was negligible. Due to the delayed phenology of

396 these trees, spiders avoided them in May when their abundance usually shows a peak (Markó et

397 al., 2009) (Fig. S8).

\section{Conclusions}

400 Our results indicate that spatio-temporal variation in environmental conditions may play an

401 important, taxon-specific role in the responses to climate-induced phenological asynchrony. For

402 instance, wild bees showed virtually no spatial variation in their responses to the phenological

403 shift of apple (Table S2), but they exhibited a profound change in species composition during the

$404 \sim 7$ weeks long flowering period. In contrast, a large amount of variation in herbivore abundance

405 was explained by the random term indicating a high spatial variation, i.e. large differences both

406 between and within orchards. Species composition of bees and aphidophagous beetles, which are

407 relatively mobile, was rather affected by the phenology of apple trees, while in case of less

408 mobile phytophagous bugs and spiders, variation was higher between orchards than between

409 treatments. These suggest that responses to climate-induced phenological changes of interacting

410 species can be scale-dependent.

411 We also highlight that species diversity was higher on manipulated trees than on control

412 ones in only one case, otherwise the phenological shift of apple trees always led to lower (or

413 similar) species diversity. The causes of altered diversity are taxon-specific. In case of spiders and

414 phytophagous bugs both the abundance and species richness were higher on the control trees and

415 only a subset of those species were found on manipulated trees. For wild bees and aphidophagous

416 beetles, the dominance of one or a few species on manipulated trees reduced diversity. We 
417 conclude that altered phenology of apple trees led to a few winners - many losers situation: it was

418 beneficial for a few arthropod species, but rather unfavorable for most of them.

419 In general, both the abundance and diversity of arthropods were more strongly affected by

420 delayed than by advanced phenology of apple trees. This may be a consequence of larger shifts in

421 the phenology of delayed compared to advanced trees, as we accounted for altered tree

422 physiology in our analyses. The larger phenological shift of delayed trees was due to the fact that

423 cold store extended the dormancy of apple trees unexpectedly long. Delayed 2 trees stayed only

424 one week longer in the cold store than Delayed1 trees, but they needed ca. 30 days from planting

425 until peak flowering, while Delayed1 trees needed only 16 days. We admit that such large

426 phenological mismatches are slightly unrealistic in the current scenarios of climate change, so the

427 results on delayed trees should be interpreted cautiously.

428 Arthropod abundance was either lower or higher, while diversity was rather similar or

429 lower on the manipulated apple trees than on control ones. In line with our hypotheses, species

430 composition of pollinator assemblages differed among treatment groups, and the most specialized

431 herbivore was negatively affected by all treatments, while less specialized herbivores were

432 affected (either positively or negatively) by only the more shifted delayed treatment. Our study

433 present clear evidence that climate-induced phenological mismatch between an orchard crop and

434 multiple groups of arthropods can have diverse effects on abundance, diversity and species

435 composition of arthropods. Consequences of these changes on ecosystem services should be 436 addressed by further research.

438 Acknowledgements

439 We are indebted to Zsolt Józan and Balázs Keresztes for the identification of bees and spiders,

440 respectively. We are grateful to the farmers for cooperation and to Lídia Homolya for her

441 assistance in the laboratory work. We used free softwares: ImageJ, LibreOffice, R, RKWard and 
442 Xubuntu.

443

444 References

445 Barboza PS, Parker KL, Hume ID. 2009. Integrative wildlife nutrition. Berlin, Germany:

$446 \quad$ Springer.

447 Bartomeus I, Ascher JS, Wagner D, Danforth BN, Colla S, Kornbluth S, Winfree R. 2011.

448 Climate-associated phenological advances in bee pollinators and bee-pollinated plants.

449 Proceedings of the National Academy Sciences of the USA 108:20645-20649. DOI:

$450 \quad 10.1073 /$ pnas. 1115559108.

451 Bartomeus I, Park MG, Gibbs J, Danforth BN, Lakso AN, Winfree R. 2013. Biodiversity ensures

452 plant-pollinator phenological synchrony against climate change. Ecology Letters 16:1331-

453 1338. DOI: 10.1111/ele.1217010.1111/ele.12170.

454 Barton K. 2014. MuMIn: Multi-model inference. R package version 1.10.5. https://cran.r-

$455 \quad$ project.org/package=MuMIn

456 Bates D, Maechler M, Bolker B, Walker S. 2015. Fitting Linear Mixed-Effects Models Using

457 Ime4. Journal of Statistical Software 67:1-48. DOI: 10.18637/jss.v067.i01.

458 Benadi G, Hovestadt T, Poethke H-J, Blüthgen N. 2014. Specialization and phenological

459 synchrony of plant-pollinator interactions along an altitudinal gradient. Journal of Animal

460 Ecology 83:639-650. DOI: 10.1111/1365-2656.12158.

461 Bewick S, Cantrell RS, Cosner C, Fagan WF. 2016. How resource phenology affects consumer

462 population dynamics. American Naturalist 187:151-166. DOI: 10.1086/684432.

463 Bogya S, Markó V, Szinetár C. 2000. Effect of pest management systems on foliage-and grass-

464 dwelling spider communities in an apple orchard in Hungary. International Journal of Pest

465 Management 46:241-250. DOI: 10.1080/09670870050206000.

466 Borbély C, Nagy C, Haltrich A, Markó V. 2017. Species composition and control of green apple 
aphids (Hemiptera, Aphididae, Aphis spp.) in apple orchards. XV. International scientific April 2017. Nitra, Slovak Republic. Book of abstracts: p 25.

Bos MM, Veddeler D, Bogdanski AK, Klein A-M, Tscharntke T, Steffan-Dewenter I, Tylianakis J. 2007. Caveats to quantifying ecosystem services: fruit abortion blurs benefits from crop pollination. Ecological Applications 17:1841-1849. DOI: 10.1890/06-1763.1.

Both C, Van Asch M, Bijlsma RG, Bug Van Den AB, Visser ME. 2009. Climate change and unequal phenological changes across four trophic levels: constraints or adaptations? Journal of Animal Ecology 78:73-83. DOI: 10.1111/j.1365-2656.2008.01458.x.

Burkle LA, Marlin JC, Knight TM. 2013. Plant-pollinator interactions over 120 years: loss of species, co-occurrence, and function. Science 339:1611-1615. DOI:

Burnham KP, Anderson DR. 2002. Model Selection and Multimodel Inference: A Practical Information-Theoretic Approach (2nd ed.), Springer-Verlag.

Cook BI, Wolkovich EM, Parmesan C. 2012. Divergent responses to spring and winter warming drive community level flowering trends. Proceedings of the National Academy Sciences of

Cross J, Fountain M, Markó V, Nagy C. 2015. Arthropod ecosystem services in apple orchards the USA 109:9000-9005. DOI: 10.1073/pnas.1118364109. and their economic benefits. Ecological Entomology 40:82-96. DOI: 10.1111/een.12234.

Doi H, Gordo O, Katano I. 2008. Heterogeneous intra-annual climatic changes drive different phenological responses at two trophic levels. Climate Research 36:181-190. DOI: interdependent phenophases in terrestrial and aquatic ecosystems. International Journal of Biometeorology 55:805-817. DOI: 10.1007/s00484-011-0426-5. 
492 Elmqvist T, Folke C, Nyström M, Peterson G, Bengtsson J, Walker B, Norberg J. 2003. Response

493 diversity, ecosystem change, and resilience. Frontiers in Ecology and the Environment

494 1:488-494. DOI: 10.1890/1540-9295.

495 Evans EW, Carlile NR, Innes MB, Pitigala N. 2013. Warm springs reduce parasitism of the cereal 496 leaf beetle through phenological mismatch. Journal of Applied Entomology 137:383-391. 497 DOI: $10.1111 /$ jen.12028.

498 Forrest JRK. 2015. Plant-pollinator interactions and phenological change: what can we learn 499 about climate impacts from experiments and observations? Oikos 124:4-13. DOI: $500 \quad$ 10.1111/oik.01386.

501 Forrest JRK, Thomson JD. 2011. An examination of synchrony between insect emergence and 502 flowering in Rocky Mountain meadows. Ecological Monographs 81:469-491. DOI:

$503 \quad 10.1890 / 10-1885.1$.

504 Földesi R, Kovács-Hostyánszki A, Kőrösi Á, Somay L, Elek Z, Markó V, Sárospataki M, Bakos

505 R, Varga Á, Nyisztor K, Báldi A. 2016. Relationships between wild bees, hoverflies and 506 pollination success in apple orchards with different landscape contexts. Agricultural and $507 \quad$ Forest Entomology 18:68-75. DOI: 10.1111/afe.12135.

508

509 Garibaldi LA, Steffan-Dewenter I, Kremen C, Morales JM, Bommarco R, Cunningham SA,

510 Carvalheiro LG, Chacoff NP, Dudenhöffer JH, Greenleaf SS, Holzschuh A, Isaacs R,

511 Krewenka K, Mandelik Y, Mayfield MM, Morandin LA, Potts SG, Ricketts TH,

512 Szentgyörgyi H, Viana BF, Westphal C, Winfree R, Klein AM. 2011. Stability of pollination

513 services decreases with isolation from natural areas despite honey bee visits. Ecology

514 Letters 14:1062-1072. DOI: 10.1111/j.1461-0248.2011.01669.x.

515 Garratt MPD, Breeze TD, Jenner N, Polce C, Biesmeijer JC, Potts SG. 2014. Avoiding a bad 516 apple: insect pollination enhances fruit quality and economic value. Agriculture, 
$517 \quad$ Ecosystems and Environment 184:34-40. DOI: 10.1016/j.agee.2013.10.032.

518 Gezon ZJ, Inouye DW, Irwin RE. 2016. Phenological change in a spring ephemeral: implications 519 for pollination and plant reproduction. Global Change Biology 22:1779-1793. DOI:

$520 \quad 10.1111 /$ gcb.13209.

521 Hegland SJ, Nielsen A, Lázaro A, Bjerknes A-L, Totland O. 2009. How does climate warming 522 affect plant-pollinator interactions? Ecology Letters 12:184-195. DOI: 10.1111/j.1461$523 \quad$ 0248.2008.01269.x.

524 Hill MO. 1973. Diversity and evenness: a unifying notation and its consequences. Ecology $525 \quad 54: 427-473$. DOI: $10.2307 / 1934352$.

526 Honek A, Martinkova Z, Dixon AF, Skuhrovec J, Roy HE, Brabec M, Pekar S. 2018. Life cycle 527 of Harmonia axyridis in central Europe. BioControl 63: 241-252. DOI: 10.1007/s10526$528 \quad 017-9864-2$.

529 Iler AM, Inouye DW, Høye TT, Miller-Rushing AJ, Burkle LA, Johnston EB. 2013. Maintenance

530 of temporal synchrony between syrphid flies and floral resources despite differential

531 phenological responses to climate. Global Change Biology 19:2348-2359. DOI:

$532 \quad 10.1111 / \mathrm{gcb} .12246$.

533 IPCC 2014. Climate Change 2014: Synthesis Report. Contribution of Working Groups I, II and 534 III to the Fifth Assessment Report of the Intergovernmental Panel on Climate Change [Core 535 Writing Team, R.K. Pachauri and L.A. Meyer (eds.)]. IPCC, Geneva, Switzerland, 151 pp. 536 Klein A-M, Vaissiere BE, Cane JH, Steffan-Dewenter I, Cunningham SA, Kremen C, Tscharntke 537 T. 2007. Importance of pollinators in changing landscapes for world crops. Proceedings of 538 the Royal Society B, Biological Sciences 274:303-313. DOI: 10.1098/rspb.2006.3721.

539 Kovács-Hostyánszki A, Haenke S, Batáry P, Jauker B, Báldi A, Tscharntke T, Holzschuh A. 540 2013. Contrasting effects of mass-flowering crops on bee pollination of hedge plants at 
541 different spatial and temporal scales. Ecological Applications 23:1938-1946. DOI:

$542 \quad 10.1890 / 12-2012.1$.

543 Kudo G, Ida TY. 2013. Early onset of spring increases the phenological mismatch between plants $544 \quad$ and pollinators. Ecology 94:2311-2320. DOI: 10.1890/12-2003.1.

545 Legendre P, Gallagher ED. 2001. Ecologically meaningful transformations for ordination of $546 \quad$ species data. Oecologia 129:271-280. DOI: 10.1007/s004420100716.

547 Leonhardt D, Gallai N, Garibaldi LA, Kuhlmann M, Klein A-M. 2013. Economic gain, stability 548 of pollination and bee diversity decrease from southern to northern Europe. Basic and $549 \quad$ Applied Ecology 14:461-471. DOI: 10.1016/j.baae.2013.06.003.

550 Mallinger RE, Gratton C. 2015. Species richness of wild bees, but not the use of managed 551 honeybees, increases fruit set of a pollinator-dependent crop. Journal of Applied Ecology $552 \quad 52: 323-330$. DOI: 10.1111/1365-2664.12377.

553 Markó V, Jenser G, Kondorosy E, Ábrahám L, Balázs K. 2013. Flowers for better pest control?

554 The effects of apple orchard ground cover management on green apple aphids (Aphis spp.)

555 (Hemiptera: Aphididae), their predators and the canopy insect community. Biocontrol

$556 \quad$ Science and Technology 23:126-145. DOI: 10.1080/09583157.2012.743972.

557 Markó V, Keresztes B, Fountain MT, Cross JV. 2009. Prey availability, pesticides and the

558 abundance of orchard spider communities. Biological Control 48:115-124. DOI:

$559 \quad 10.1016 /$ j.biocontrol.2008.10.002.

560 Memmott J, Craze PG, Waser NM, Price MV. 2007. Global warming and the disruption of plant561 pollinator interactions. Ecology Letters 10:710-717. DOI: 10.1111/j.1461-

$562 \quad$ 0248.2007.01061.x.

563 Miller-Rushing AJ, Høye TT, Inouye DW, Post E. 2010. The effects of phenological mismatches 564 on demography. Philosophical Transactions of the Royal Society B, Biological Sciences $565 \quad 365: 3177-3186$. DOI: 10.1098/rstb.2010.0148. 
566 Mitchell RJ, Flanagan RJ, Brown BJ, Waser NM, Karron JD. 2009. New frontiers in competition

567 for pollination. Annals of Botany 103:1403-1413. DOI: 10.1093/aob/mcp062.

568 Moise ERD, Henry HAL. 2010. Like moths to a street lamp: exaggerated animal densities in

569 plot-level global change field experiments. Oikos 119:791-795. DOI: 10.1111/j.1600-

$570 \quad$ 0706.2009.18343.x.

571 Nagy C, Cross JV, Markó V. 2013. Sugar feeding of the common black ant, Lasius niger (L.), as a

572 possible indirect method for reducing aphid populations on apple by disturbing ant-aphid

573 mutualism. Biological Control 65:24-36. DOI: 10.1016/j.biocontrol.2013.01.005.

574 Oksanen J, Blanchet FG, Friendly M, Kindt R, Legendre P, McGlinn D, Minchin PR, O'Hara RB,

575 Simpson GL, Solymos P, Stevens MHH, Szoecs E, Wagner H 2017. vegan: Community

576 Ecology Package. R package version 2.4-4. https://cran.r-project.org/package=vegan

577 Oliver T, Heard MS, Isaac NJB, Roy DB, Procter D, Eigenbrod F, Freckleton R, Hector A, Orme

578 DL, Petchey OL, Proenca V, Raffaelli D, Suttle KB, Mace GM, Martín-López B,

579 Woodcock BA, Bullock JM. 2015. Biodiversity and resilience of ecosystem functions.

$580 \quad$ Trends in Ecology and Evolution 30:673-684. DOI: 10.1016/j.tree.2015.08.009.

581 Ovaskainen O, Skorokhodova S, Yakovleva M, Sukhov A, Kutenkov A, Kutenkova N,

582 Shcherbakov A, Meyke E, del Mar Delgado M. 2013. Community-level phenological

583 response to climate change. Proceedings of the National Academy Sciences of the USA

584 110:13434-13439. DOI: 10.1073/pnas.1305533110.

585 O’neal ME, Landis DA, Isaacs R. 2002. An inexpensive, accurate method for measuring leaf area 586 and defoliation through digital image analysis. Journal of Economic Entomology 95:1190-

587 1194. DOI: 10.1603/0022-0493-95.6.1190.

588 Parsche S, Fründ J, Tscharntke T. 2011. Experimental environmental change and mutualistic vs.

589 antagonistic plant flower-visitor interactions. Perspectives in Plant Ecology, Evolution and

$590 \quad$ Systematics 13:27-35. DOI: 10.1016/j.ppees.2010.12.001. 
591 Petanidou T, Kallimanis AS, Tzanopoulos J, Sgardelis SP, Pantis JD. 2008. Long-term

592 observation of a pollination network: fluctuation in species and interactions, relative

593 invariance of network structure and implications for estimates of specialization. Ecology

594 Letters 11:564-575. DOI: 10.1111/j.1461-0248.2008.01170.x.

595 Post E, Forchhammer MC. 2008. Climate change reduces reproductive success of an Arctic

596 herbivore through trophic mismatch. Philosophical Transactions of the Royal Society B,

597 Biological Sciences 363:2367-2373. DOI: 10.1098/rstb.2007.2207.

598 Primack RB, Ibáñez I, Higuchi I, Lee SD, Miller-Rushing AJ, Wilson AM, Silander JA. 2009.

$599 \quad$ Spatial and interspecific variability in phenological responses to warming temperatures.

600 Biological Conservation 142:2569-2577. DOI: 10.1016/j.biocon.2009.06.003.

601 R Core Team 2017 R: A language and environment for statistical computing. R Foundation for

602 Statistical Computing, Vienna, Austria. https:/www.R-project.org/

603 Rafferty NE, CaraDonna PJ, Burkle LA, Iler AM, Bronstein JL. 2013. Phenological overlap of

604 interacting species in a changing climate: an assessment of available approaches. Ecology

$605 \quad$ and Evolution 3:3183-3193. DOI: 10.1002/ece3.668.

606 Rafferty NE, Ives AR. 2011. Effects of experimental shifts in flowering phenology on plant-

607 pollinator interactions. Ecology Letters 14:69-74. DOI: 10.1111/j.1461-0248.2010.01557.x.

608 Rafferty NE, Ives AR. 2012. Pollinator effectiveness varies with experimental shifts in flowering

609 time. Ecology 93:803-814. DOI: 10.1890/11-0967.1.

610 Riedinger V, Renner M, Rundlöf M, Steffan-Dewenter I, Holzschuh A. 2014. Early mass-

611 flowering crops mitigate pollinator dilution in late-flowering crops. Landscape Ecology

$612 \quad 29: 425-435$. DOI: $10.1890 / 12-2012.1$.

613 Rosa García RR, Miñarro M. 2014. Role of floral resources in the conservation of pollinator

614 communities in cider-apple orchards. Agriculture, Ecosystems and Environment 
616 Schneider CA, Rasband WS, Eliceiri KW. 2012. NIH Image to ImageJ: 25 years of image 617 analysis. Nature Methods 9:671-675. DOI: :10.1038/nmeth.2089.

618 Schwartz MD, Ahas R, Aasa A. 2006. Onset of spring starting earlier across the Northern 619 Hemisphere. Global Change Biology 12:343-351. DOI: 10.1111/j.1365$620 \quad$ 2486.2005.01097.x.

621 Skaug H, Fournier D, Bolker B, Magnusson A, Nielsen A. 2015. Generalized Linear Mixed 622 Models using 'AD Model Builder'. R package version 0.8.2.

623 Steffan-Dewenter I, Schiele S. 2008. Do resources or natural enemies drive bee population 624 dynamics in fragmented habitats? Ecology 89:1421-1432. DOI: 10.1890/06-1323.1.

625 Stenseth NC, Mysterud A. 2002. Climate, changing phenology, and other life-history traits: non626 linearity and match-mismatch to the environment. Proceedings of the National Academy 627 Sciences of the USA 99:13379-13381. DOI: 10.1073/pnas.212519399.

628 Stoeckli S, Mody K, Dorn S. 2008. Aphis pomi (Hemiptera: Aphididae) population development, 629 shoot characteristics, and antibiosis resistance in different apple genotypes. Journal of 630 Economic Entomology 101:1341-1348. DOI: 10.1603/0022-0493.

631 Thackeray SJ, Sparks TH, Frederiksen M, Burthe S, Bacon PJ, Bell JR, Botham MS, Brereton 632 TM, Bright PW, Carvalho L, Clutton-Brock T, Dawson A, Edwards M, Elliott JM, 633 Harrington R, Johns D, Jones ID, Jones JT, Leech DI, Roy DB, Scott WA, Smith M, 634 Smithers RJ, Winfield IJ, Wanless S. 2010. Trophic level asynchrony in rates of 635 phenological change for marine, freshwater and terrestrial environments. Global Change 636 Biology 16:3304-3313. DOI: 10.1111/j.1365-2486.2010.02165.x.

637 Thomson DJ. 2010. Flowering phenology, fruiting success and progressive deterioration of 638 pollination in an early-flowering geophyte. Philosophical Transactions of the Royal Society 639 B, Biological Sciences 365:3189-3199. DOI: 10.1098/rstb.2010.0115. 
640 Torchio PF. 1991. Bees as crop pollinators and the role of solitary species in changing 641 environments. Acta Horticulturae 288:49-61.

642 Tóthmérész B. 1995. Comparison of different methods for diversity ordering. Journal of 643 Vegetation Science 6:283-290. DOI: 10.2307/3236223.

644 Van Asch M, Van Tienderen PH, Holleman LJM, Visser ME. 2007. Predicting adaptation of 645 phenology in response to climate change, an insect herbivore example. Global Change 646 Biology 13:1596-1604. DOI: 10.1111/j.1365-2486.2007.01400.x.

647 Van Asch M, Visser ME. 2007. Phenology of forest caterpillars and their host trees: the 648 importance of synchrony. Annual Review of Entomology 52:37-55. DOI:

$649 \quad$ 10.1146/annurev.ento.52.110405.091418.

650 Vazquez DP, Morris WF, Jordano P. 2005. Interaction frequency as a surrogate for the total effect 651 of animal mutualists on plants. Ecology Letters 8:1088-1094. DOI: 10.1111/j.1461$652 \quad$ 0248.2005.00810.x.

653 Visser ME, Holleman LJM. 2001. Warmer springs disrupt the synchrony of oak and winter moth 654 phenology. Proceedings of the Royal Society B, Biological Sciences 268:289-294. DOI:

$655 \quad 10.1098 / \mathrm{rspb} .2000 .1363$.

656 Wachmann E, Melber A, Deckert J 2006 Wanzen. Band 1. Dipsocoromorpha, Nepomorpha, 657 Gerromorpha, Leptopodomorpha, Cimicomorpha (Teil 1). Die Tierwelt Deutschlands. 77. 658 Teil. Goecke and Evers, Keltern, 264 pp.

659 Westphal C, Steffan-Dewenter I, Tscharntke T. 2003. Mass flowering crops enhance pollinator 660 densities at a landscape scale. Ecology Letters 6:961-965. DOI: 10.1046/j.1461$661 \quad$ 0248.2003.00523.x.

662 Winder M, Schindler DE. 2004. Climate change uncouples trophic interactions in an aquatic 663 ecosystem. Ecology 85:2100-2106. DOI: 10.1890/04-0151.

664 Zuur AF, Ieno EN, Walker NJ, Saveliev AA, Smith GM 2009. Mixed Effects Models and Exten- 
665 sions in Ecology with R. Springer, New York, USA.

666 
Figure 1

Apple tree condition in each of the five experimental treatments.

(A) Number of flowers. (B) Leaf size. (C) Shoot growth. (D) Fruit set (assessed in one orchard only, $n=62$ ). Grey boxes represent treatments significantly different from the control. A: box spacing is proportional to the time elapsed between peak flowering in each treatment.
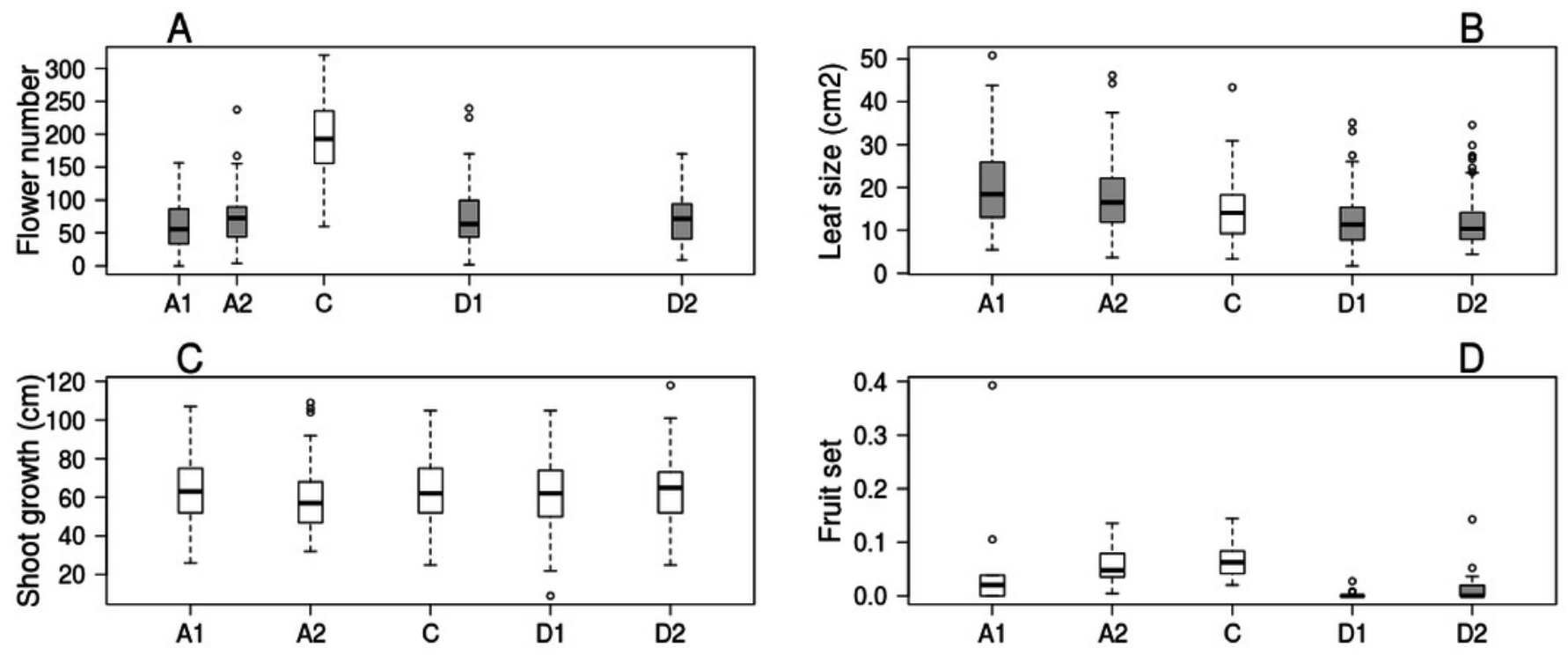
Figure 2

Abundance of pollinators in each of the five experimental treatments.

Box spacing is proportional to the time elapsed between peak flowering in each treatment. Grey boxes represent those treatments where parameter estimates were significantly different from the control, based on the best models that included the number of flowers as well (see text). Note that this does not mean that pollinator abundance was significantly different in these treatments. Dashed lines indicate the beginning and end of May.

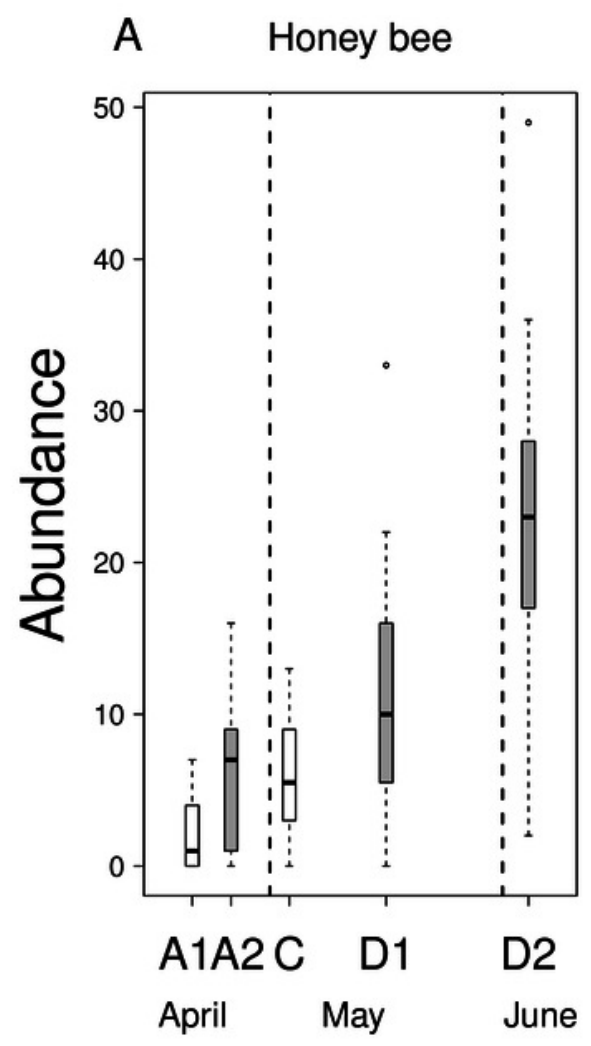

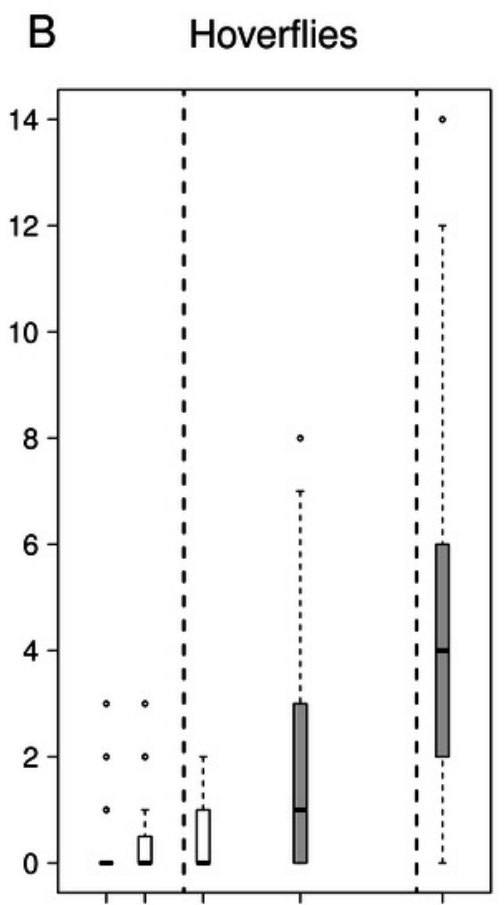

A1A2C D1 D2 April

May

June

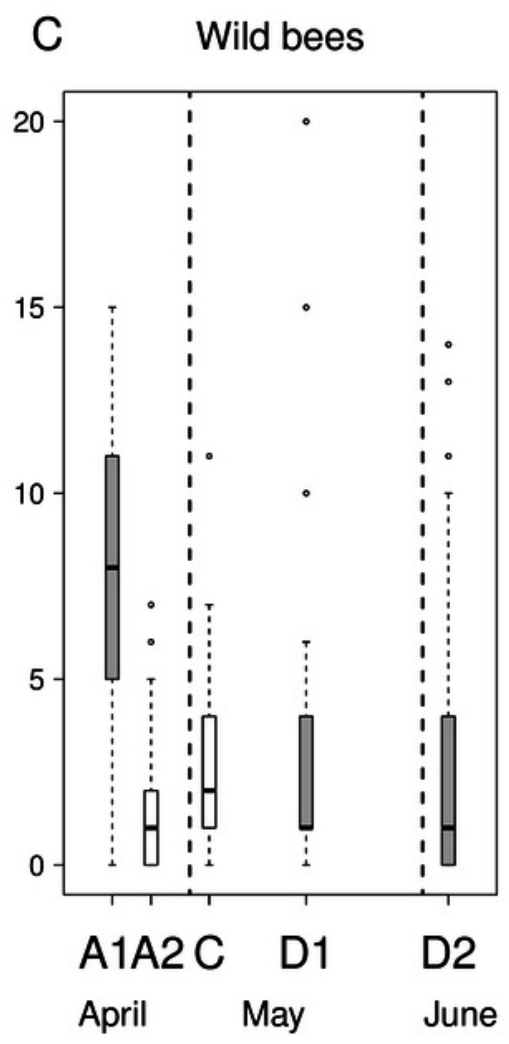


Figure 3

"Rényi" diversity profiles of wild bees, phytophagous bugs, aphidophagous beetles and spiders in each of the five experimental treatments along the scale parameter (a).

$a=0: \log ($ species richness); $a=1:$ Shannon-Wiener index; $a=2:$ Simpson index.
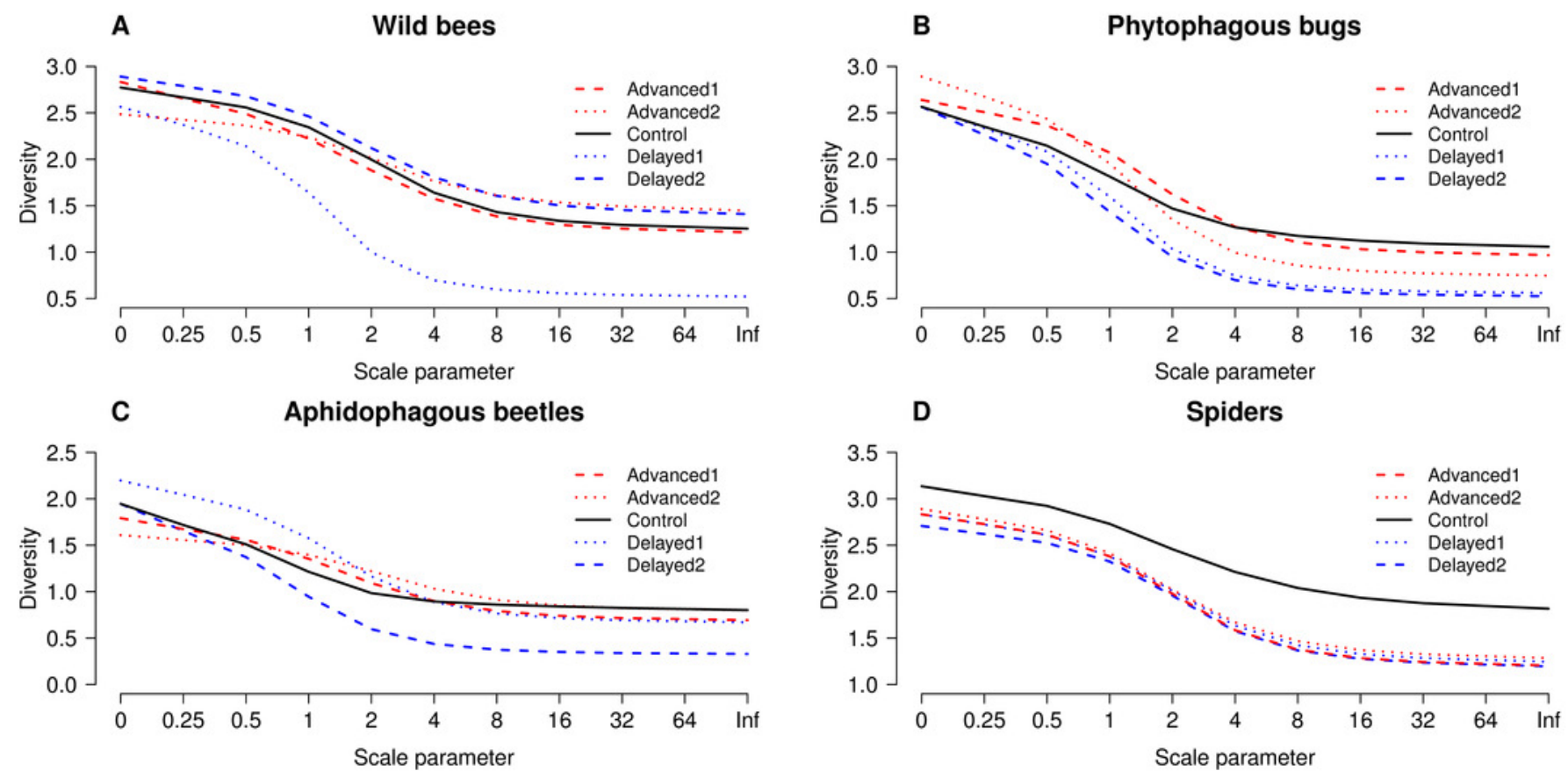


\section{Figure 4}

Abundance/occurrence (mean $\pm S E$ ) of herbivores $(A-C)$ and natural enemies $(D-F)$ in each of the five experimental treatments.

Grey bars/boxes represent treatments significantly different from the control. Red dots on panel B show mean proportion of growing shoots. A: A. pomorum was found in one orchard only $(n=47)$. C: only non-zero data are shown $(n=116)$.
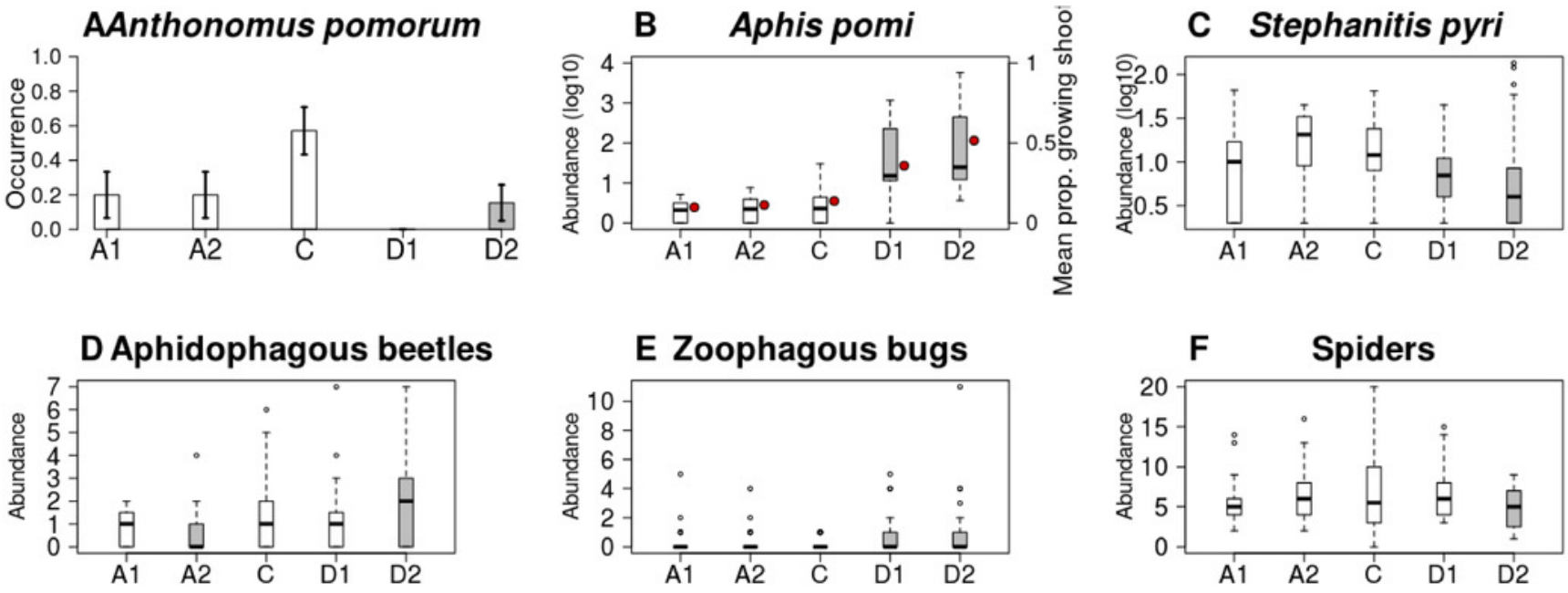
Table $\mathbf{1}$ (on next page)

Apple tree phenology in each of the five treatments. 
Manuscript to be reviewed

Treatment Abbrevi- Number of Date of planting Peak flowering, Days of ation trees outdoors pollinator flowering sampling

\begin{tabular}{lccccc}
\hline Advanced1 & A1 & 31 & 17.04 .2013 & $19-20.04 .2013$ & 6 \\
Advanced2 & A2 & 31 & 19.04 .2013 & $24-25.04 .2013$ & 6 \\
Control & C & 42 & 05.04 .2013 & $2-3.05 .2013$ & 5 \\
Delayed1 & D1 & 39 & 30.04 .2013 & $17-19.05 .2013$ & 6 \\
Delayed2 & D2 & 39 & 07.05 .2013 & $7-8.06 .2013$ & 7
\end{tabular}




\section{Table 2 (on next page)}

Parameter estimates (SE) of the best models for each response variable.

Control was the reference level of treatment in all models, significant terms are bold. Red upward and blue downward arrows indicate that the response variable was significantly higher or lower, respectively, in the given treatment than in the control group. \# indicates that an additional covariate also had significant effect on the response variable (number of flowers for pollinators, PGS for aphids and prey abundance for natural enemies; see text). * indicates that the response variable in a given treatment was zero on all trees. See Table S2 for full model outputs. Diversity was compared using Rényi's diversity profiles (Fig. 3), thus no parameter estimates are available. Arrows indicate that diversity profiles were below (blue) or above (red) that of the control group. 


\section{PeerJ}

\section{Manuscript to be reviewed}

Advanced1 Advanced2 Delayed1 Delayed2

\begin{tabular}{|c|c|c|c|c|c|}
\hline \multirow{4}{*}{ Tree condition } & Flower number & $-6.35(0.64) \downarrow$ & $-5.64(0.63) \downarrow$ & $-5.71(0.59) \downarrow$ & $-5.63(0.59) \downarrow$ \\
\hline & Fruit set & $-0.04(0.42)$ & $-0.03(0.41)$ & $-2.95(1.27) \downarrow$ & $-1.18(0.58) \downarrow$ \\
\hline & Leaf area & $5.7(0.67) \uparrow$ & $3.2(0.67) \uparrow$ & $-2.4(0.63) \downarrow$ & $-2.8(0.63) \downarrow$ \\
\hline & Shoot growth & $0.38(2.70)$ & $-3.8(2.70)$ & $-1.66(2.53)$ & $-0.44(2.53)$ \\
\hline \multirow{3}{*}{ Pollinators } & Honey bee abundance \# & $-0.34(0.23)$ & $0.47(0.17) \uparrow$ & $1.13(0.15) \uparrow$ & $1.89(0.14) \uparrow$ \\
\hline & Hoverfly abundance \# & $-0.20(0.48)$ & $-0.02(0.43)$ & $1.46(0.31) \uparrow$ & $2.46(0.29) \uparrow$ \\
\hline & Wild bee abundance \# & $2.03(0.23) \uparrow$ & $0.16(0.29)$ & $0.81(0.24) \uparrow$ & $0.67(0.26) \uparrow$ \\
\hline \multirow{5}{*}{ Herbivores } & A. pomorum occurrence & $-1.67(0.96)$ & $-1.67(0.96)$ & $\downarrow^{*}$ & $-1.99(0.94) \downarrow$ \\
\hline & A. pomorum infected buds & $-1.09(0.49) \downarrow$ & $-0.13(0.35)$ & $\downarrow^{*}$ & $\downarrow^{*}$ \\
\hline & Aphid abundance \# & $0.43(0.30)$ & $0.15(0.34)$ & $0.77(0.19) \uparrow$ & $-1.32(0.29) \uparrow$ \\
\hline & S. pyri abundance & $-0.15(0.11)$ & $0.04(0.11)$ & $-0.26(0.11) \downarrow$ & $-0.33(0.11) \downarrow$ \\
\hline & Phytophagous bug abundance & $-0.42(0.24)$ & $0.01(0.22)$ & $-0.29(0.22)$ & $-0.22(0.21)$ \\
\hline \multirow{3}{*}{ Natural enemies } & Aphidophagous beetle abundance \# & $-0.15(0.23)$ & $-0.54(0.26) \downarrow$ & $0.36(0.26)$ & $0.99(0.26) \uparrow$ \\
\hline & Zoophagous bug abundance & $0.84(0.57)$ & $0.73(0.57)$ & $1.72(0.51) \uparrow$ & $1.74(0.51) \uparrow$ \\
\hline & Spider abundance \# & $-0.16(0.14)$ & $-0.104(0.14)$ & $-0.09(0.13)$ & $-0.57(0.15) \downarrow$ \\
\hline \multirow{4}{*}{ Diversity } & Wild bees & & & $\downarrow$ & $\uparrow$ \\
\hline & Phytophagous bugs & & & $\downarrow$ & $\downarrow$ \\
\hline & Aphidophagous beetles & & & & $\downarrow$ \\
\hline & Spiders & $\downarrow$ & $\downarrow$ & $\downarrow$ & $\downarrow$ \\
\hline
\end{tabular}

